\title{
Fractional-Derivative Maxwell Kelvin Model for "5+4" Viscoelastic Damping Wall Subjected to Large Deformation
}

\author{
Junhong Xu, ${ }^{1}$ Aiqun $\mathrm{Li}^{1,2}$ and Yang Shen ${ }^{3}$ \\ ${ }^{1}$ School of Civil Engineering, Southeast University, Nanjing, Jiangsu 210096, China \\ ${ }^{2}$ Beijing University of Civil Engineering and Architecture, Beijing 100044, China \\ ${ }^{3}$ Key Laboratory of Ministry of Education for Geomechanics and Embankment Engineering, Hohai University, Nanjing 210098, China
}

Correspondence should be addressed to Junhong Xu; xujunhong0321@126.com

Received 17 February 2016; Revised 16 May 2016; Accepted 29 May 2016

Academic Editor: Stefano de Miranda

Copyright (C) 2016 Junhong Xu et al. This is an open access article distributed under the Creative Commons Attribution License, which permits unrestricted use, distribution, and reproduction in any medium, provided the original work is properly cited.

\begin{abstract}
Considering the larger vibration amplitude and several viscoelastic material layers, a fractional-derivative Maxwell Kelvin (FDMK) viscoelastic mechanical model is proposed for " $5+4$ " viscoelastic damping wall, which is used for vibration control of building structures. The development of the model is based on in-parallel combination of fractional Maxwell model and fractional Kelvin model. The proposed model is experimentally validated and very good agreement between predicted and experimental results was obtained. The results confirm that the FDMK model is accurate in simulating the hysteresis properties of the " $5+4$ " viscoelastic damping wall under large deformation. From the areas of the experimental and theoretical hysteresis loops, under $300 \%$ strain, the predicted result is the most accurate in prediction of the energy dissipation and the second is the prediction under $450 \%$ strain. Moreover, from the comparisons of dynamic properties (storage modulus, loss modulus, etc.), the FDMK model works satisfactorily. The FDMK model is more sensitive in energy dissipation than in energy storage.
\end{abstract}

\section{Introduction}

Protection of the mechanical response of the building structures subjected to earthquake has become an increasingly critical issue. Viscoelastic dampers have long been used in controlling the vibration in civil engineering [1]. For example, 260 viscoelastic dampers were installed in the Columbia Center building in Seattle in order to decrease wind-induced vibration. A pioneer application can be traced back to New York in 1969 where around 10000 viscoelastic dampers were installed in the towers of the World Trade Center to resist wind loads [2]. Similar implementation of viscoelastic dampers for seismic mitigation can be also found in [3]. However, general application of the structures with added viscoelastic dampers cannot be significantly developed without comprehensive understanding of the constitutive behavior of viscoelastic dampers. Current researches on constitutive modeling mainly focus on the classical and fractional-derivative models which can be found in [4-11].

Classical constitutive modeling is the diverse combination of springs and dashpots [12-16], for example, the
Maxwell (M) and Kelvin (K) models, Burger model, generalized Maxwell model (GMM), and other models [17, 18]. The literature [17] studied shear-type buildings with Maxwell model-based brace-damper systems. The generalized Maxwell model (GMM) was experimentally verified by simulating the behavior of a fluid damper [18]. Although these models are simple and can be easily applied in practical engineering, studies [19-21] have shown that the parameters obtained under low-frequency vibration could be inaccurate when vibration frequency increased to a higher extent. A twoparameter cooling law was proposed to offer a dependable estimate of the internal temperature of fluid dampers [20]. Under this kind of situation, more complex model parameters should be included or otherwise the original model would lose its accuracy $[6,22]$. However, this can make the classical model too cumbersome for general application. To solve the problem, fractional models, such as the fractional Kelvin model and fractional Maxwell model, were proposed and received increasingly considerable attention [23-25]. The literature [23] presented an approximate analytical solution 
to calculate the force of viscous dampers subjected to lowfrequency motions. A family of parameters identification methods were proposed for the Maxwell and Kelvin fractional models [24]. The fractional-derivative models can accurately capture the viscoelastic damping properties of the dampers by using even fewer model parameters.

The dynamic characteristics of a viscoelastic damper largely depend on the geometry of the device once the material is determined [26]. The classical and fractionalderivative models $[6,27,28]$ mentioned above were mainly verified based on the " $3+2$ " (composed of two viscoelastic layers bonded with three parallel steel plates) viscoelastic dampers. The literature [6] discussed two specific examples by constitutive modeling of viscoelastic solid damper and viscoelastic liquids damper. Considering the larger vibration amplitude, the literature [29] proposed a " $5+4$ " (composed of four viscoelastic layers bonded with five parallel steel plates) super large viscoelastic damping wall (VDW) under large deformation (at 225\%, 300\%, and 450\% strain). Compared with the traditional viscoelastic damping device, " $5+4$ " VDW has a substantial number of advantages. For example, " $5+4$ " VDW can supply large space for doors or windows in a building. The placement of " $5+4$ " VDW can be also equal to the interstory displacement so as to improve the efficiency of energy dissipation with a great deal of application potential.

However, the constitutive model of " $5+4$ " VDW is not yet sufficiently validated by test results. Due to the large deformation and four viscoelastic material layers, highly nonlinear viscoelastic behavior may exist in such damper. The objective of this paper is to propose a reasonable mathematical model for " $5+4$ " VDW. As will be shown, the proposed model, called FDMK, will be derived by parallel combination of the Maxwell and Kelvin components. It will be validated by characterizing various damping properties (storage modulus, loss modulus, storage stiffness, loss stiffness, equivalent damping coefficient, and loss factor) of the " $5+4$ " VDW.

The paper is organized as follows. In Section 2, constitutive model of " $5+4$ " VDW is derived. In Section 3, parameters of the derived model are identified with nonlinear least square method by using MATLAB (version 7.0). Then, the model behavior is investigated in the frequency domain and verified by fitting the experimental data.

\section{Dynamic Characteristics and Modeling of " $5+4$ " VDW}

Experimental studies have demonstrated that the damping properties of viscoelastic dampers are related not only to the viscoelastic material, but also to the damper deformation. The structure diagram of the " $5+4$ " VDW can be found in Figure $1(\mathrm{a})$ and the three-dimensional view of the corresponding loading device can be found in Figure 1(b). The upper steel plate is connected to the flange structures (green part in Figure 1(b)). The details are shown in Figure 1(c). The bottom steel plate is fixed at the test bed (purple part in Figure 1(b)). The details are shown in Figure 1(d). Experimental details, such as the test material, test setup, and test results, are available in [29]. Figure 3 shows the force-displacement hysteresis loops measured in a sinusoidal test by PA30-240 (Tobul Accumulator Inc., as shown in Figure 2). It is quite evident that increasing the deformation generally results in larger cycles, that is, higher temporal shifting between stress and strain. It can be also observed that the force-deformation loops exhibit high nonlinearity.

The FDMK model proposed by this paper is considered as in-parallel combination of the fractional Maxwell model and the fractional Kelvin model, as schematically shown in Figure 4.

The Riemann-Liouville fractional derivative is defined as [30]

$$
\begin{aligned}
D^{r}[f(t)] & =\frac{1}{\Gamma(1-r)} \frac{d}{d t} \int_{0}^{t} \frac{f(t-\tau)}{\tau^{r}} d \tau \\
& =\frac{d}{d t} \int_{0}^{t} I_{r}(\tau) f(t-\tau) d \tau \\
& =I_{r}(t) f(0)+\int_{0}^{t} I_{r}(\tau) \frac{d}{d t} f(t-\tau) d \tau,
\end{aligned}
$$

where $r$ is the fractional order of derivative with respect to time $t$ and $0<r<1$. $\Gamma$ is the gamma function. And $\Gamma(z)=$ $\int_{0}^{\infty} t^{z-1} e^{-t} d t, z>0$.

The constitutive equation of the Abel dashpot is defined as

$$
\sigma(t)=\eta D^{r}[\varepsilon(t)]=\eta I_{r}(t) * d \varepsilon(t) .
$$

So, the fractional Kelvin model in Figure 4 can be written as

$$
\sigma_{1}(t)=\eta_{1} D^{r}\left[\varepsilon_{1}(t)\right]+G_{1} \varepsilon_{1}(t),
$$

where $\eta_{1}$ is the viscosity coefficient of the Abel dashpots and $G_{1}$ is the elastic coefficient in the fractional Kelvin model.

The fractional Maxwell model in Figure 4 can be written as

$$
\sigma_{2}(t)+\frac{\eta_{2}}{G_{2}} D^{r}\left[\sigma_{2}(t)\right]=\eta_{2} D^{r}\left[\varepsilon_{2}(t)\right]
$$

where $\eta_{2}$ is the viscosity coefficient of the Abel dashpots and $G_{2}$ is the elastic coefficient in the fractional Maxwell model.

Due to parallel combination, (3) and (4) can be treated as a set of equations which can be written in the form of

$$
\begin{aligned}
\sigma_{1}(t) & =\eta_{1} D^{r}\left[\varepsilon_{1}(t)\right]+G_{1} \varepsilon_{1}(t), \\
\sigma_{2}(t)+\frac{\eta_{2}}{G_{2}} D^{r}\left[\sigma_{2}(t)\right] & =\eta_{2} D^{r}\left[\varepsilon_{2}(t)\right] \\
\varepsilon(t) & =\varepsilon_{1}(t)=\varepsilon_{2}(t) \\
\sigma(t) & =\sigma_{1}(t)+\sigma_{2}(t) .
\end{aligned}
$$

By rearranging (5), the relationship between stress and strain can be explicitly formulated as

$$
\sigma(t)=\Theta \varepsilon(t),
$$




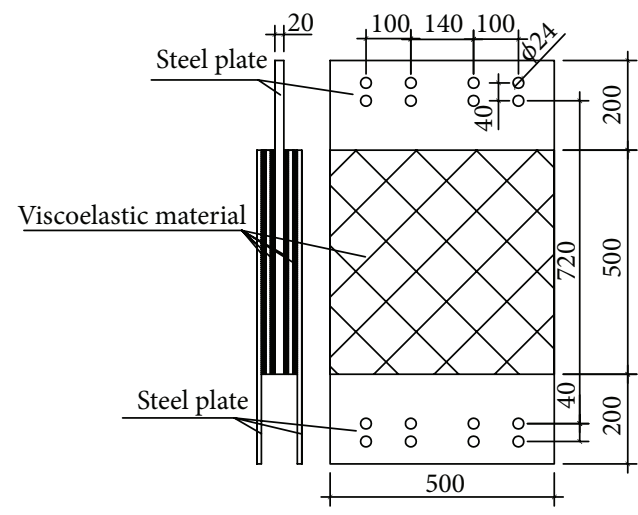

(a) Geometry [29] (unit: $\mathrm{mm}$ )

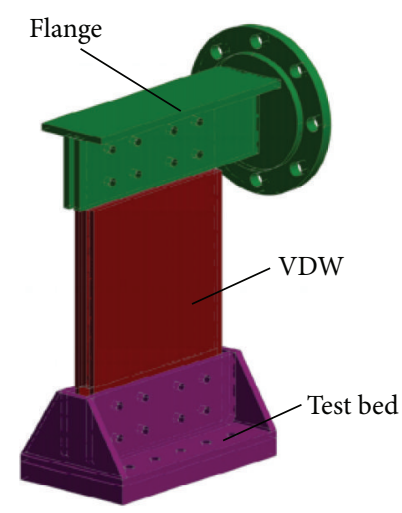

(b) Three-dimensional view of loading device
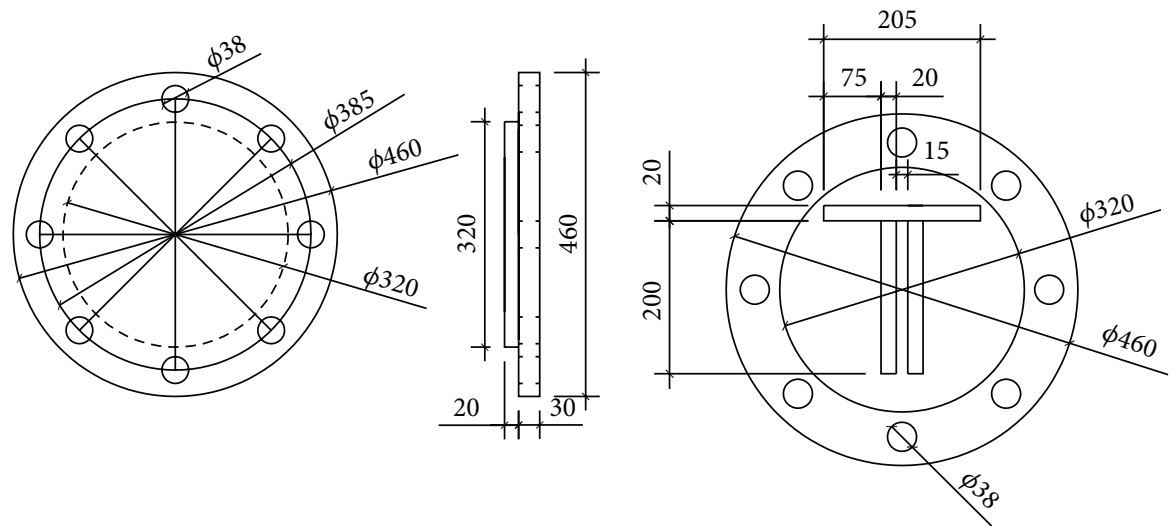

(c) The connection between the upper steel plate and the flange
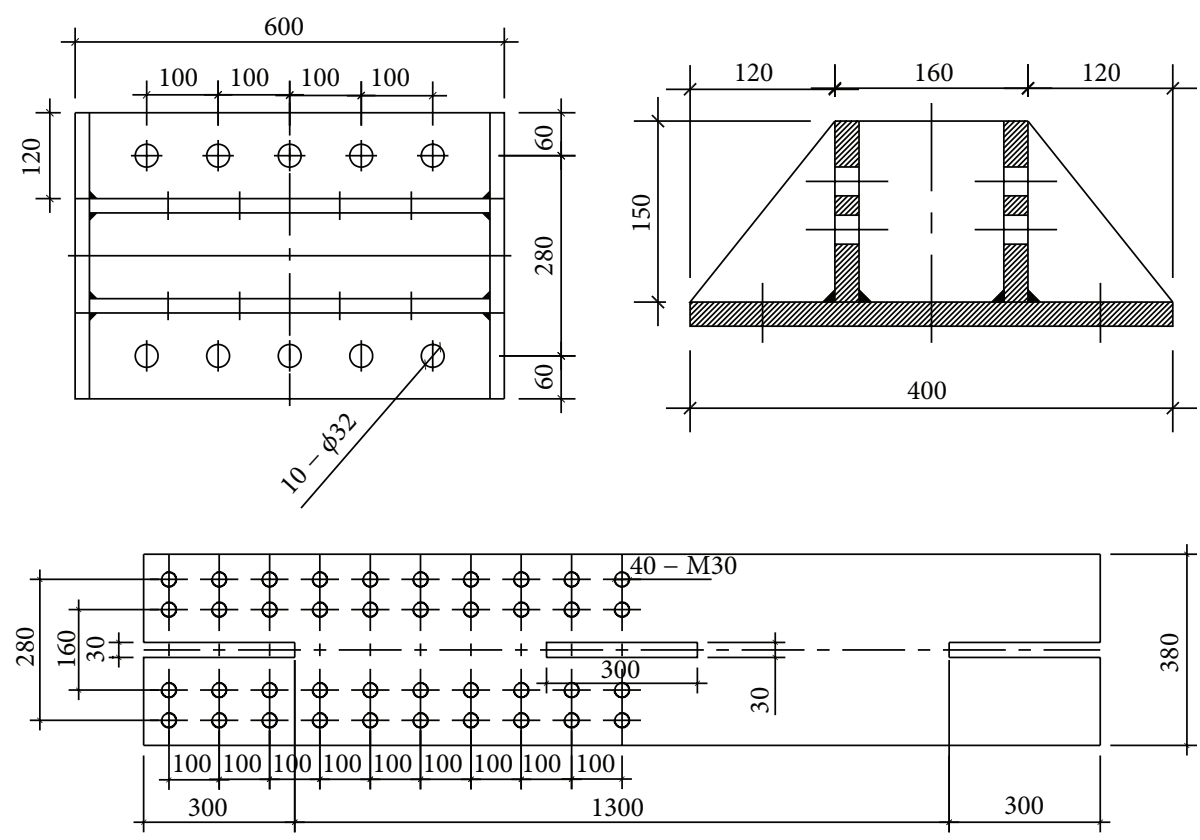

(d) The connection between the bottom steel plate and the test bed

FIGURE 1: “5+4” super large viscoelastic damping wall. 


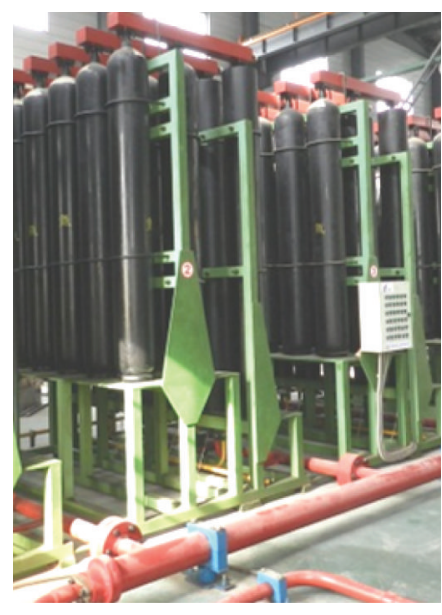

(a) High pressure nitrogen gas bottle

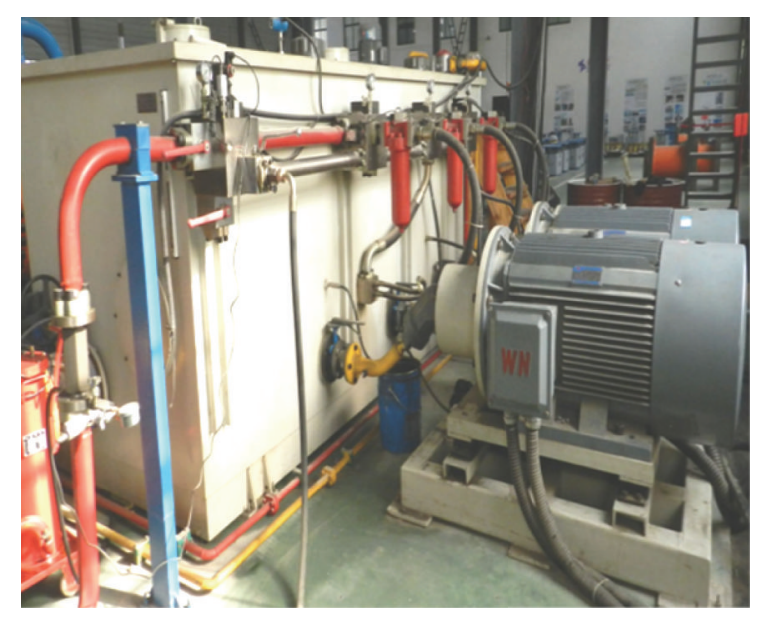

(b) Piston energy storage system

FIgURE 2: Test power source.

where

$$
\Theta=\frac{G_{2} \eta_{1} \eta_{2} D^{r}\left(G_{1}+\eta_{1} D^{r}\right)}{\left(G_{1} \eta_{2}+\eta_{1} \eta_{2} D^{r}\right)\left(G_{2} \eta_{2}+\eta_{2}^{2} D^{r}\right)+G_{2} \eta_{2}^{2} D^{r}} .
$$

The Fourier transform of (6a) and (6b) is written as

$$
\begin{aligned}
& \tilde{\sigma}(\omega) \\
& =\frac{G_{2} \eta_{1} \eta_{2}(i \omega)^{r}\left[G_{1}+\eta_{1}(i \omega)^{r}\right] \widetilde{\varepsilon}(\omega)}{\left[G_{1} \eta_{2}+\eta_{1} \eta_{2}(i \omega)^{r}\right]\left[G_{2} \eta_{2}+\eta_{2}^{2}(i \omega)^{r}\right]+G_{2} \eta_{2}^{2}(i \omega)^{r}} .
\end{aligned}
$$

The symbol $i$ denotes the imaginary unit; $\omega$ denotes the circular frequency, where $\omega=2 \pi f$, and $f$ is the frequency. $\widetilde{\sigma}(\omega)$ and $\widetilde{\mathcal{E}}(\omega)$ are the Fourier transforms of the stress and strain histories, respectively.

By performing inverse Fourier transform of (7), the following relationships $\left(G^{\prime}\right.$, the storage modulus of FDMK model, and $G^{\prime \prime}$, the loss modulus of FDMK model) can be obtained:

$$
\begin{aligned}
G^{\prime} & =\frac{\left(G_{1} G_{2} \eta_{2}^{2} \omega^{r} \sin (r \pi / 2)+G_{2} \eta_{2} \eta_{1}^{2} \omega^{r} \sin r \pi\right)}{\cos r \pi}, \\
G^{\prime \prime} & =\frac{\left(G_{1} G_{2} \eta_{2} \eta_{1} \omega^{r} \cos (r \pi / 2)+G_{2} \eta_{1} \eta_{2}^{2} \omega^{r} \cos (r \pi / 2)+\omega^{2 r} \cos (r \pi / 2)\right)}{\sin r \pi} .
\end{aligned}
$$

So, the loss factor $\eta$ can be expressed as

$$
\eta=\frac{G^{\prime \prime}}{G^{\prime}}=\frac{\left(G_{1} G_{2} \eta_{2} \eta_{1} \omega^{r} \cos (r \pi / 2)+G_{2} \eta_{1} \eta_{2}^{2} \omega^{r} \cos (r \pi / 2)+\omega^{2 r} \cos (r \pi / 2)\right) \cos r \pi}{\left(G_{1} G_{2} \eta_{2}^{2} \omega^{r} \sin (r \pi / 2)+G_{2} \eta_{2} \eta_{1}^{2} \omega^{r} \sin r \pi\right) \sin r \pi}
$$

The viscoelastic damper can be characterized by the storage stiffness $K_{d}^{\prime}$ and loss stiffness $K_{d}^{\prime \prime}$ which are related to $G^{\prime}$ and $G^{\prime \prime}$ as

$$
\begin{aligned}
K_{d}^{\prime} & =\frac{G^{\prime} A}{h}=\frac{\left(G_{1} G_{2} \eta_{2}^{2} \omega^{r} \sin (r \pi / 2)+G_{2} \eta_{2} \eta_{1}^{2} \omega^{r} \sin r \pi\right) A}{h \cos r \pi}, \\
K_{d}^{\prime \prime} & =\frac{G^{\prime \prime} A}{h}=\frac{\left(G_{1} G_{2} \eta_{2} \eta_{1} \omega^{r} \cos (r \pi / 2)+G_{2} \eta_{1} \eta_{2}^{2} \omega^{r} \cos (r \pi / 2)+\omega^{2 r} \cos (r \pi / 2)\right) A}{h \sin r \pi},
\end{aligned}
$$




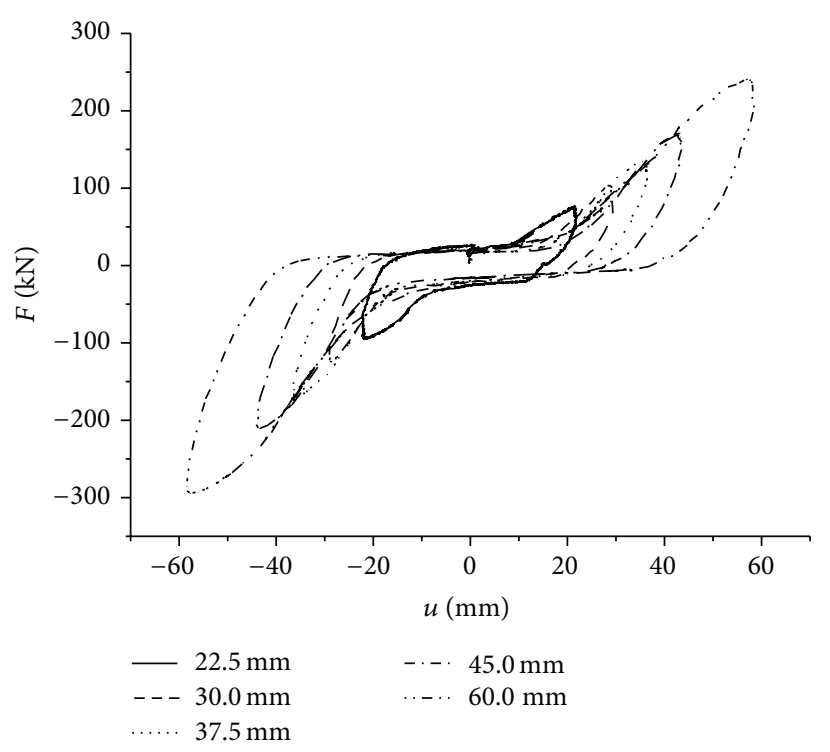

(a) $0.5 \mathrm{~Hz}$

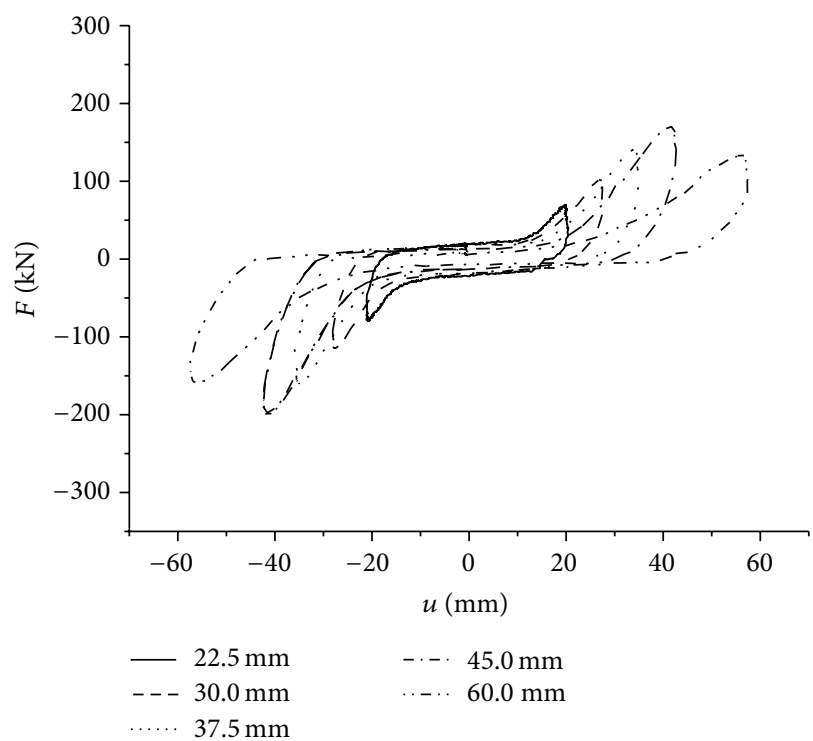

(c) $1.5 \mathrm{~Hz}$

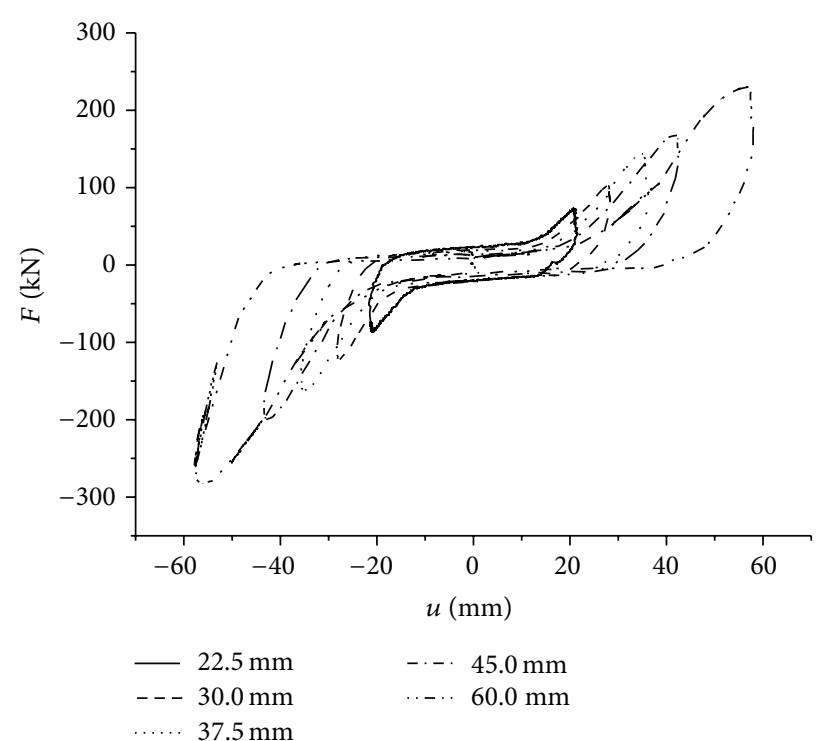

(b) $1.0 \mathrm{~Hz}$

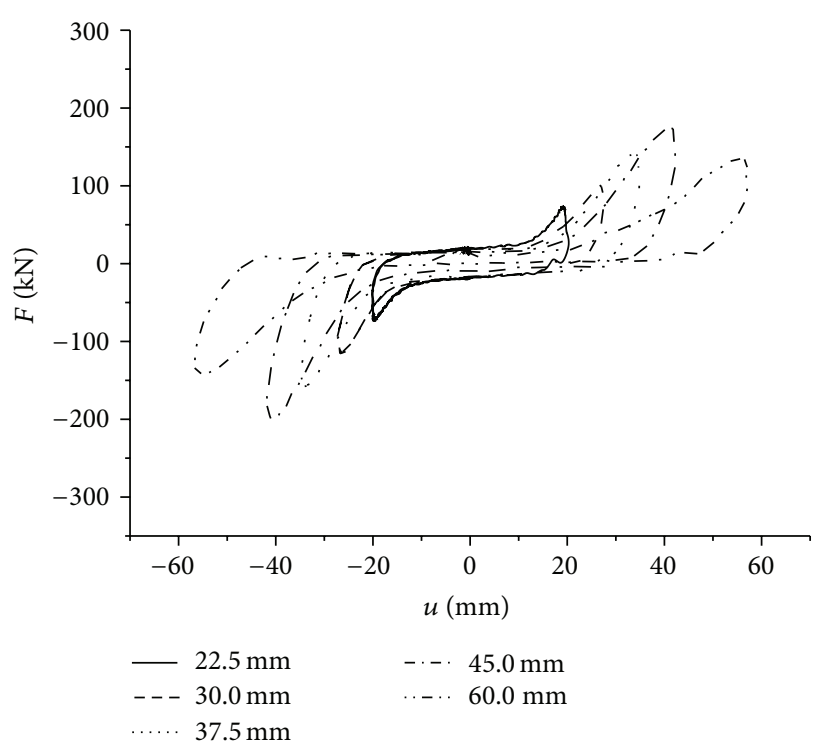

(d) $2.0 \mathrm{~Hz}$

FIGURE 3: $F-u$ hysteresis curves of VDW at different frequencies and displacement values.

where $A$ is the total shear area and $h$ is the thickness of the viscoelastic damping material slab. The values of $A$ and $h$ are $1000000 \mathrm{~mm}^{2}$ and $10 \mathrm{~mm}$, respectively. The equipment damping coefficient $C_{d}$ is defined by

$$
C_{d}=\frac{K_{d}^{\prime \prime}}{\omega}=\frac{\left(G_{1} G_{2} \eta_{2} \eta_{1} \omega^{r} \cos (r \pi / 2)+G_{2} \eta_{1} \eta_{2}^{2} \omega^{r} \cos (r \pi / 2)+\omega^{2 r} \cos (r \pi / 2)\right) A}{h \omega \sin r \pi}
$$

\section{Model Validation}

In this study, the FDMK model characterized by (8), (9), (10), and (11) will be employed to simulate the viscoelastic damping behavior of " $5+4$ " VDW under large deformation. As shown above, there are only five characteristic parameters $\left(\eta_{1}, G_{1}, \eta_{2}\right.$, $G_{2}$, and $r$ ) to be determined. The test results of " $5+4$ " VDW by $\mathrm{Xu}$ and Li [29] as shown in Tables 1, 2, and 3 are used to validate the proposed model.

An important problem of the FDMK model is the identification of the model parameters from experimental data. Pritz [4] discussed the method of parameters identification of five-parameter fractional-derivative model, which utilized the asymptotic properties of the storage and loss modulus 


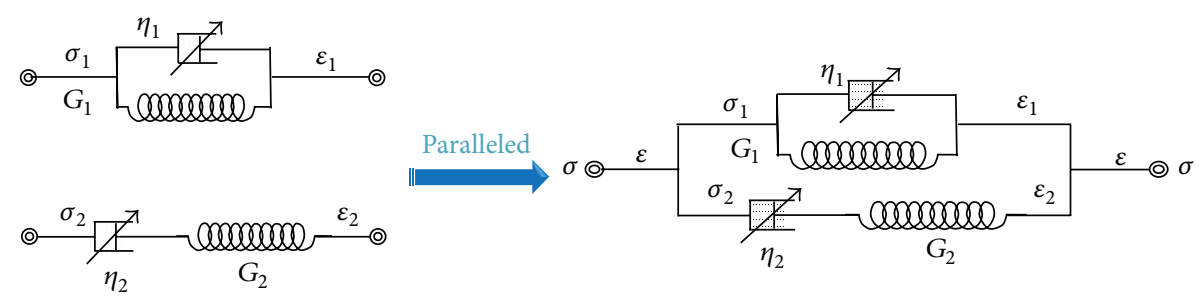

FIGURE 4: A schematic show of FDMK viscoelastic mechanical model.

TABLE 1: Properties of " $5+4$ " viscoelastic damping wall (at $225 \%$ strain and $21.2^{\circ} \mathrm{C}$ ).

\begin{tabular}{lcccccc}
\hline Frequency $(\mathrm{Hz})$ & $G^{\prime}(\mathrm{MPa})$ & $G^{\prime \prime}(\mathrm{MPa})$ & $\eta(\mathrm{MPa} \cdot \mathrm{s})$ & $K_{d}^{\prime}(\mathrm{kN} / \mathrm{mm})$ & $K_{d}^{\prime \prime}(\mathrm{kN} / \mathrm{mm})$ & $C_{d}(\mathrm{kN} \cdot \mathrm{s} / \mathrm{mm})$ \\
\hline$f=0.5$ & 2.65 & 0.76 & 0.29 & 2.65 & 0.76 & 1.05 \\
$f=1.0$ & 1.79 & 1.05 & 0.59 & 1.79 & 1.34 & 0.85 \\
$f=1.5$ & 1.34 & 0.85 & 0.63 & 1.16 & 0.89 & 0.70 \\
$f=2.0$ & 1.16 & 0.89 & 0.77 & 1.00 & 0.91 & 0.57 \\
$f=5.0$ & 1.00 & 0.91 & 0.91 & 0.96 & 0.94 \\
$f=10.0$ & 0.96 & 0.94 & 0.98 & & 0.40 \\
\hline
\end{tabular}

TABLE 2: Properties of “ $5+4$ " viscoelastic damping wall (at $300 \%$ strain and $21.2^{\circ} \mathrm{C}$ ).

\begin{tabular}{lcccccc}
\hline Frequency $(\mathrm{Hz})$ & $G^{\prime}(\mathrm{MPa})$ & $G^{\prime \prime}(\mathrm{MPa})$ & $\eta(\mathrm{MPa} \cdot \mathrm{s})$ & $K_{d}^{\prime}(\mathrm{kN} / \mathrm{mm})$ & $K_{d}^{\prime \prime}(\mathrm{kN} / \mathrm{mm})$ & $C_{d}(\mathrm{kN} \cdot \mathrm{s} / \mathrm{mm})$ \\
\hline$f=0.5$ & 2.36 & 0.67 & 0.29 & 2.36 & 2.69 & 0.67 \\
$f=1.0$ & 2.69 & 0.63 & 0.23 & 1.34 & 0.63 \\
$f=1.5$ & 1.89 & 0.63 & 0.33 & 0.63 & 0.42 \\
$f=2.0$ & 2.43 & 0.62 & 0.26 & 2.43 & 0.62 & 0.61 \\
$f=5.0$ & 2.20 & 0.61 & 0.28 & 2.20 & 0.51 & 0.28 \\
$f=10.0$ & 2.10 & 0.50 & 0.24 & 2.10 & 0.25 \\
\hline
\end{tabular}

TABLe 3: Properties of “ $5+4$ " viscoelastic damping wall (at $450 \%$ strain and $21.2^{\circ} \mathrm{C}$ ).

\begin{tabular}{|c|c|c|c|c|c|c|}
\hline Frequency $(\mathrm{Hz})$ & $G^{\prime}(\mathrm{MPa})$ & $G^{\prime \prime}(\mathrm{MPa})$ & $\eta(\mathrm{MPa} \cdot \mathrm{s})$ & $K_{d}^{\prime}(\mathrm{kN} / \mathrm{mm})$ & $K_{d}^{\prime \prime}(\mathrm{kN} / \mathrm{mm})$ & $C_{d}(\mathrm{kN} \cdot \mathrm{s} / \mathrm{mm})$ \\
\hline$f=0.5$ & 3.54 & 0.29 & 0.08 & 3.54 & 0.29 & 0.58 \\
\hline$f=1.0$ & 3.20 & 0.29 & 0.09 & 3.20 & 0.29 & 0.19 \\
\hline$f=1.5$ & 2.89 & 0.32 & 0.11 & 2.89 & 0.32 & 0.21 \\
\hline$f=2.0$ & 2.72 & 0.33 & 0.12 & 2.72 & 0.33 & 0.17 \\
\hline$f=5.0$ & 2.71 & 0.34 & 0.13 & 2.71 & 0.34 & 0.16 \\
\hline$f=10.0$ & 2.65 & 0.36 & 0.14 & 2.65 & 0.36 & 0.11 \\
\hline
\end{tabular}

functions. Makris [31] mentioned one more detailed description of the least square method for identification procedure. Park [6] determined the parameters of two mechanical models of viscoelastic dampers. In this paper, the parameters are obtained by using nonlinear least square method within MATLAB to analyze a set of storage modulus and loss modulus data (defined as the square root of the sum of squares of storage modulus and loss modulus data). In the least square method, the error between the model and the experimental complex modulus $G^{*}\left(G^{*}=G^{\prime}+i G^{\prime \prime}\right)$ is minimized in order to search the model parameters. The optimal parametric values of the FDMK model are obtained by the minimum of the following objective function (see (12)) which is defined by the error functional minimum between the theoretical and experimental data:

$$
\min \widetilde{I}\left(G_{1}, G_{2}, \eta_{1}, \eta_{2}, r\right)=\sum_{i=1}^{6}\left(r_{i}-s_{i}\right)^{2} .
$$

Note that $i=1-6$, since there are a total of 6 excitation frequencies in the test, that is, $0.5,1.0,1.5,2.0,5.0$, and $10.0 \mathrm{~Hz}$. Symbols $r_{i}$ and $s_{i}$ denote the data point obtained from 
TABLE 4: Best-fitting parameters of the FDMK model.

\begin{tabular}{cccccc}
\hline & $G_{1}(\mathrm{MPa})$ & $G_{2}(\mathrm{MPa})$ & $\eta_{1}(\mathrm{MPa} \cdot \mathrm{s})$ & $\eta_{2}(\mathrm{MPa} \cdot \mathrm{s})$ & $r$ \\
\hline Value & 8.69 & 3.58 & 0.75 & 0.98 & 0.60 \\
\hline
\end{tabular}

TABLE 5: Comparison of the areas of the experimental and theoretical hysteresis loops.

\begin{tabular}{lccc}
\hline $\begin{array}{l}\text { Frequency } \\
(\mathrm{Hz})\end{array}$ & $\begin{array}{c}\text { Theoretical value } \\
(\mathrm{kN} \cdot \mathrm{mm})\end{array}$ & $\begin{array}{c}\text { Experimental value } \\
(\mathrm{kN} \cdot \mathrm{mm})\end{array}$ & $\Delta$ \\
\hline $0.5(225 \%)$ & 2279 & 2413 & $5.6 \%$ \\
$1.5(225 \%)$ & 2104 & 2249 & $6.9 \%$ \\
$0.5(300 \%)$ & 2849 & 2826 & $0.8 \%$ \\
$1.5(300 \%)$ & 2445 & 2540 & $3.7 \%$ \\
$0.5(450 \%)$ & 5240 & 5394 & $2.9 \%$ \\
$1.5(450 \%)$ & 4427 & 4530 & $2.3 \%$ \\
\hline
\end{tabular}

the experiment and the FDMK model for the $i$ th excitation frequency, respectively. The results of the parameters identification are shown in Table 4, together with their normalized error.

3.1. Comparisons of Hysteresis Loops between Test and Simulation. Figure 5 compares the experimental hysteresis loops with the simulation by the FDMK model for the excitation frequencies of 0.5 and $1.5 \mathrm{~Hz}$ under $225 \%$ strain, $300 \%$ strain, and $450 \%$ strain. The red solid lines in Figure 5 represent the experimental loops, while the dotted lines depict the theoretical loops simulated by using the parameters listed in Table 4. Notably, the experimental and theoretical loops have almost the same relative displacement and force. Figure 5 also shows that the hysteresis loops are Z-shaped, whereas both loops do not show an inclined elliptical shape and behaved in a nonlinear viscoelastic manner because the viscoelastic materials belonged to Si content [32]. Figure 5(a) demonstrates that the simulated results obtained by the FDMK model underestimate the damper force in the third quadrant at $225 \%$ strain and frequency of $0.5 \mathrm{~Hz}$ but overestimate the damper force in the fourth quadrant at $225 \%$ strain and frequency of $1.5 \mathrm{~Hz}$. Figures 5(c), 5(d), 5(e), and 5(f) illustrate that the theoretical results are in good agreement with the experimental loops under large deformation.

Moreover, the area of a hysteresis loop is equivalent to the ability of the energy dissipated by the damper. Table 5 compares the area of the theoretical loops to the experimental loops under frequencies 0.5 and $1.5 \mathrm{~Hz}$ at three strains, $225 \%$, $300 \%$, and $450 \%$, respectively. Note that $\Delta$ in Table 5 denotes the error percentage of the dissipated energy simulated by the FDMK model. The error percentage is defined as

$$
\Delta=\left|\frac{A_{\text {Exp }}-A_{\text {The }}}{A_{\text {Exp }}}\right| \times 100 \%,
$$

where $A_{\text {Exp }}$ and $A_{\text {The }}$ denote the areas of the experimental and theoretical hysteresis loops, respectively. The areas of the experimental and theoretical hysteresis loops were integrated by MATLAB programs and the values are shown in Table 5 . Based on the error percentage calculated by (13), under $300 \%$ strain, the predicted result is the most accurate in prediction of the energy dissipation and the second is the prediction under $450 \%$ strain. From the area values, at $225 \%$ strain and the frequency of $0.5 \mathrm{~Hz}$, the model underestimates the experimental results, while, at $225 \%$ strain and the frequency of $1.5 \mathrm{~Hz}$, the model overestimates the experimental results. This is consistent with the results presented in Figure 5.

3.2. Comparisons of Mechanical Properties. The mechanical properties of viscoelastic damping wall are important technical parameters used for the designing of vibration reduction in engineering structures. So, this section will demonstrate the model prediction of the mechanical properties, typically the storage modulus $G^{\prime}$, the loss modulus $G^{\prime \prime}$, the storage stiffness $K_{d}^{\prime}$, the loss stiffness $K_{d}^{\prime \prime}$, the equivalent damping coefficient $C_{d}$, and the loss factor $\eta$. These values from experiment are presented in Tables 1-3. The FDMK viscoelastic mechanical model representations for $G^{\prime}$ and $G^{\prime \prime}$ are given in the form of (8). Additionally, $K_{d}^{\prime}$ and $K_{d}^{\prime \prime}$ are related to $G^{\prime}$ and $G^{\prime \prime}$ as (10).

The results obtained at $225 \%$ and $450 \%$ strains will be briefly described. A comparison of the storage modulus resulting from the FDMK model with the corresponding experimental results is presented in Figure 6. A similar comparison for the loss modulus is shown in Figure 7. Note that, in view of (10), the storage stiffness $K_{d}^{\prime}$ and the loss stiffness $K_{d}^{\prime \prime}$ are linear functions of the storage modulus $G^{\prime}$ and the loss modulus $G^{\prime \prime}$, respectively. The curve shapes for $G^{\prime}$ and $K_{d}^{\prime}$ are similar to each other; likewise, $G^{\prime \prime}$ and $K_{d}^{\prime \prime}$ share the same trends. The presented results demonstrate that the FDMK model could reasonably describe the modulus of the damping wall under large deformation. The presented model works satisfactorily. Moreover, the values of $G^{\prime \prime}$ and $K_{d}^{\prime \prime}$ calculated by FDMK model are closer to the experimental test than the values of $G^{\prime}$ and $K_{d}^{\prime}$. This indicates that the FDMK model is more sensitive in energy dissipation than in energy storage. As shown in Figure 7(a), the $G^{\prime \prime}$ value under $\omega=1.0$ exhibits mutation. This may be explained as follows: the mutation possibility of the energy dissipation of the viscoelastic material used for VDW has occurred under $\omega=1.0$. These general trends can provide a beneficial guideline for engineers to predict the behavior of the damping wall subjected to different excitation.

The plot of the equivalent damping coefficient versus frequency is shown in Figure 8. It can be observed that the equivalent damping coefficient $C_{d}$ of the viscoelastic damping wall can be well characterized by the FDMK model. The results of $\eta$ (Figure 9) show some departures from the FDMK representation, but the overall trend of the curve coincides with the experimental results. Therefore, it is suggested that the design values could be increased in actual design of " $5+4$ " viscoelastic damping wall under large deformation. 

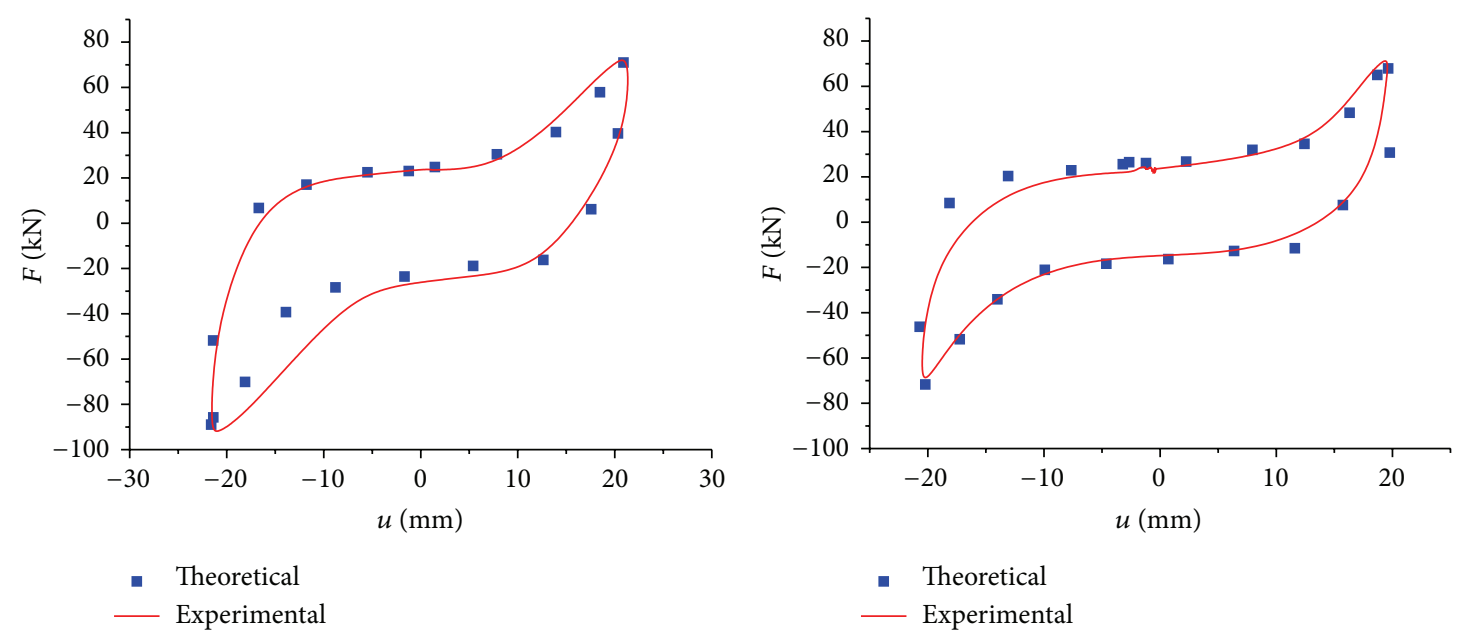

(a) At $225 \%$ strain, frequency $0.5 \mathrm{~Hz}$

(b) At $225 \%$ strain, frequency $1.5 \mathrm{~Hz}$
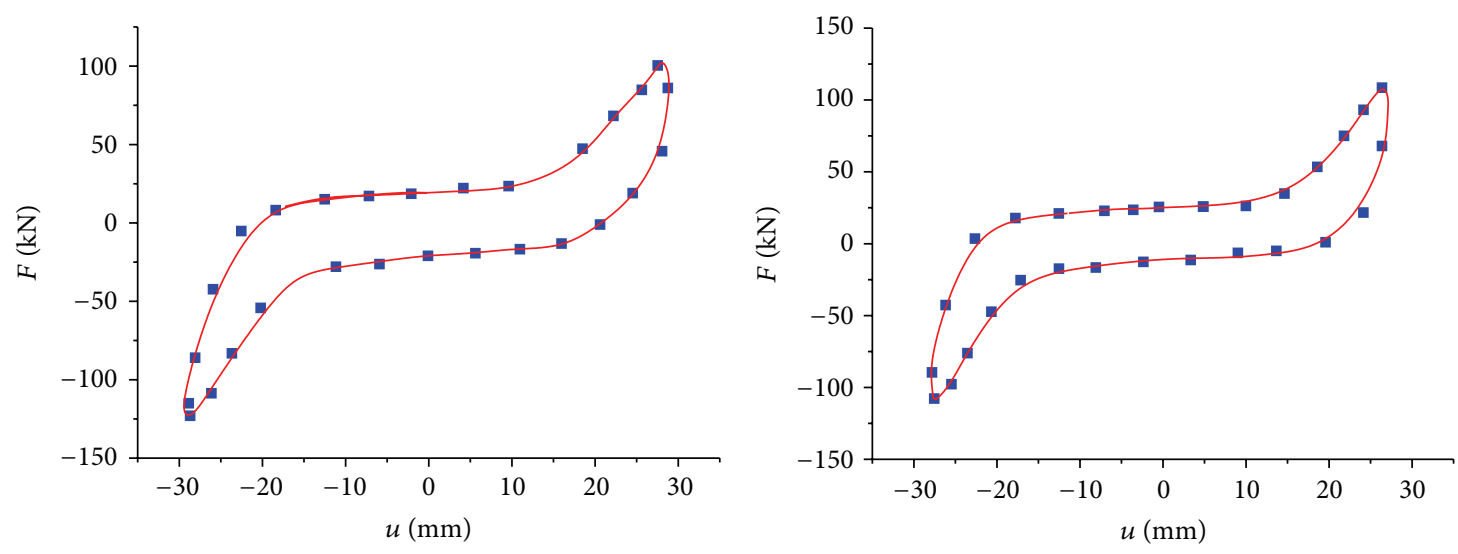

- Theoretical

- Experimental

(c) At $300 \%$ strain, frequency $0.5 \mathrm{~Hz}$

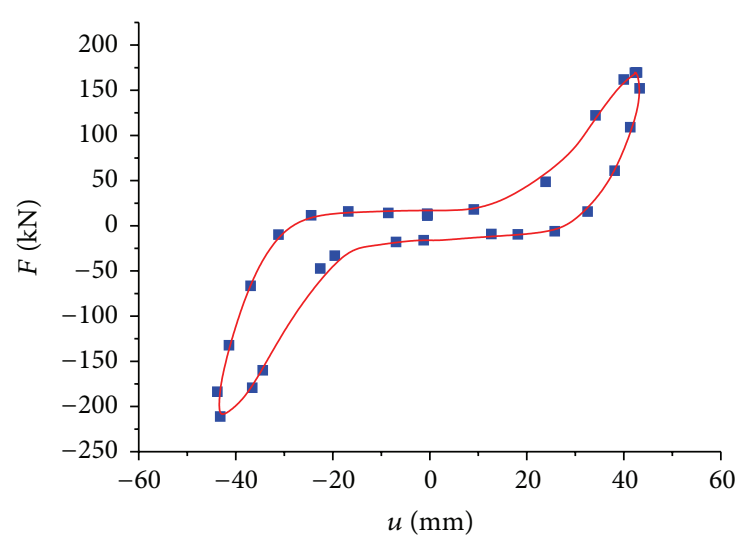

- Theoretical

— Experimental

- Theoretical

- Experimental

(d) At $300 \%$ strain, frequency $1.5 \mathrm{~Hz}$

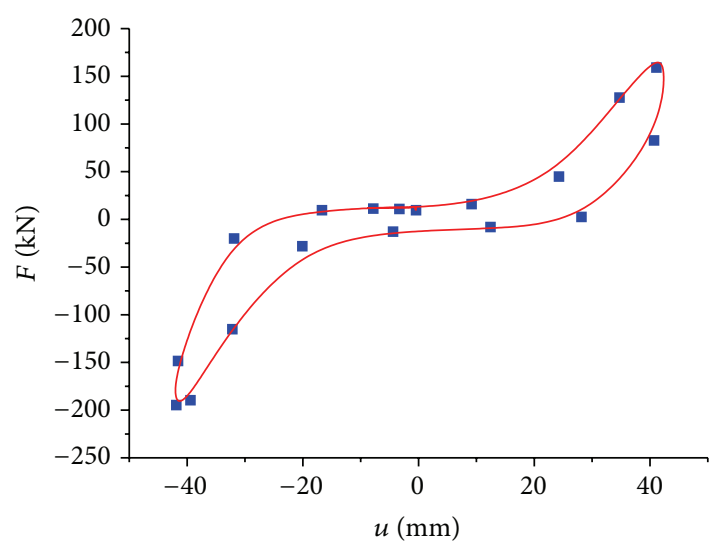

- Theoretical

_ Experimental

(e) At $450 \%$ strain, frequency $0.5 \mathrm{~Hz}$

(f) At $450 \%$ strain, frequency $1.5 \mathrm{~Hz}$

FIGURE 5: Comparison between the experimental and numerically reconstructed hysteresis loops. 


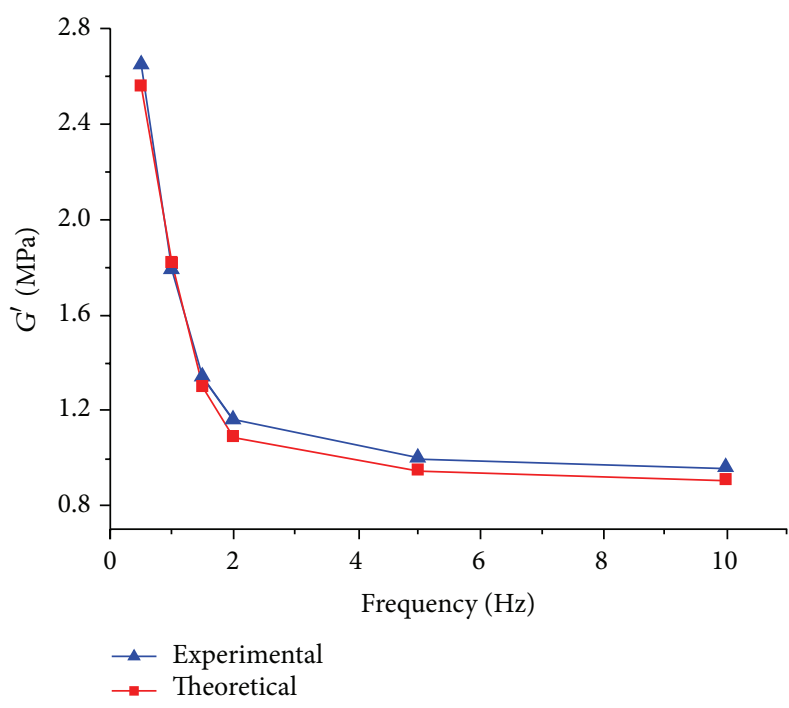

(a) At $225 \%$ strain

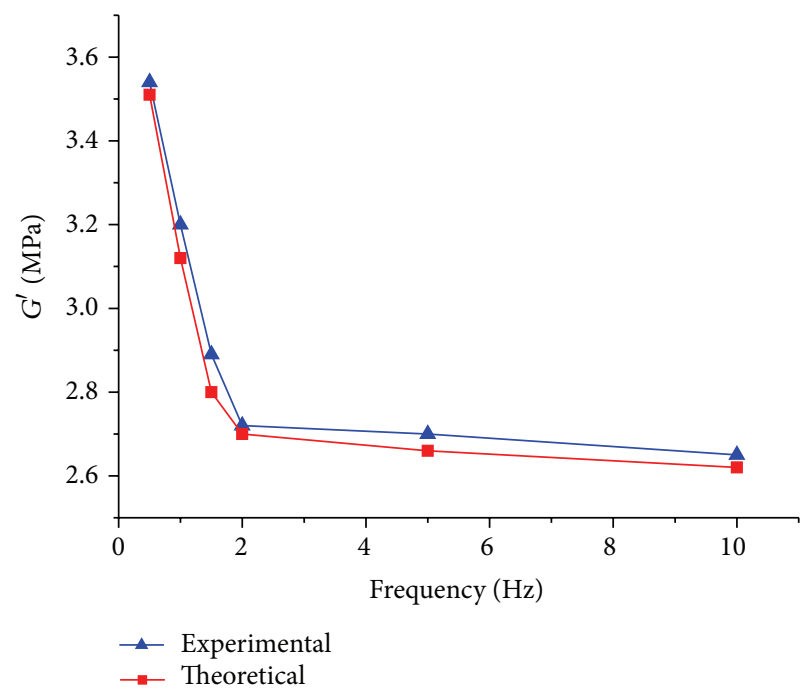

(b) At $450 \%$ strain

FIGURE 6: Model simulation of the storage modulus.

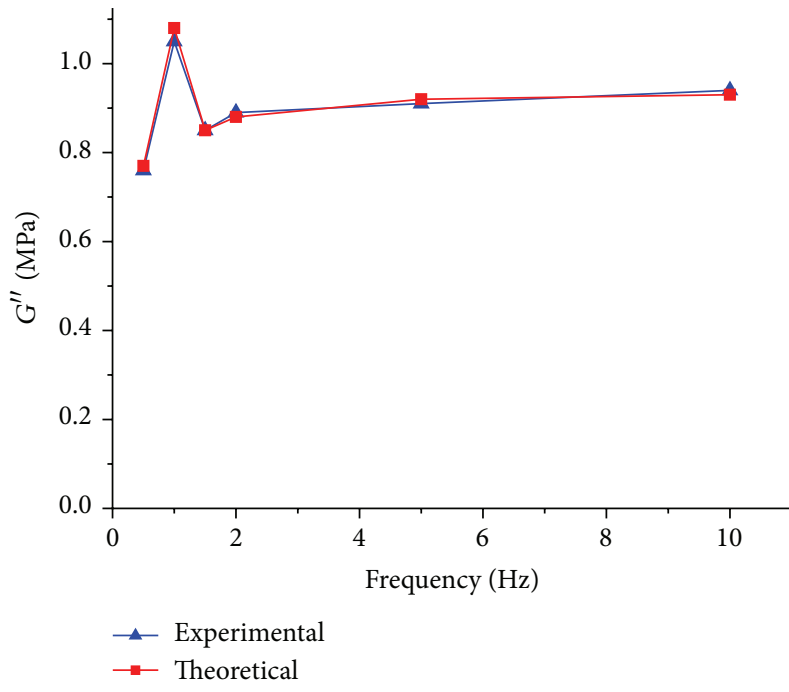

(a) At $225 \%$ strain

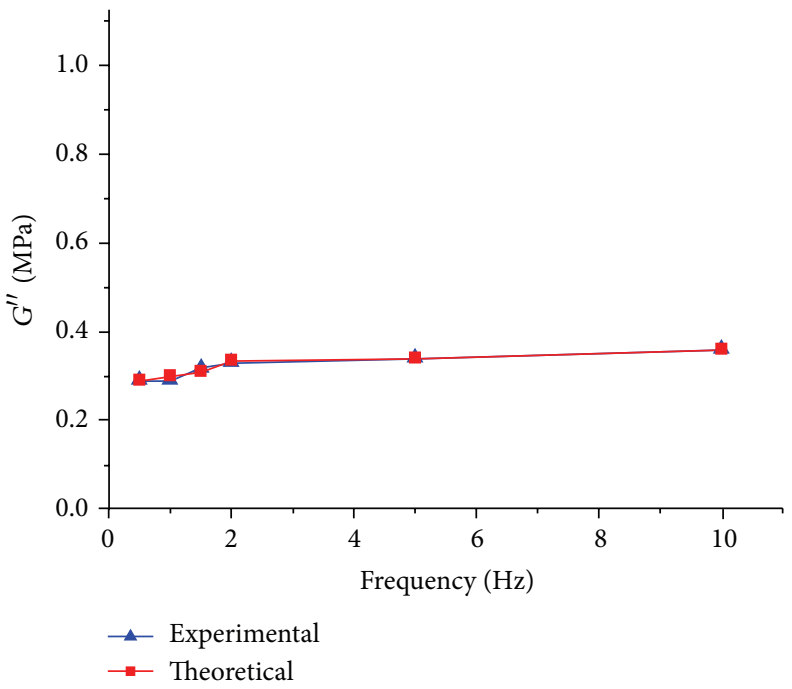

(b) At $450 \%$ strain

FIgURE 7: Model simulation of the loss modulus.

\section{Conclusions}

This paper proposed a FDMK model for " $5+4$ " viscoelastic damping wall subjected to large deformation. The FDMK model was composed of a fractional Kelvin model and a fractional Maxwell model, which were connected in a parallel way. Comparison between the experimental and predicted results showed that the theoretical results matched very well the experimental hysteresis loops under the large deformation. From the areas of the experimental and theoretical hysteresis loops, under $300 \%$ strain, the predicted result was the most accurate in prediction of the energy dissipation and the second was the prediction under $450 \%$ strain.

Moreover, the FDMK model was more sensitive in energy dissipation than in energy storage. The design values could be increased in actual design of " $5+4$ " viscoelastic damping wall under large deformation.

\section{Competing Interests}

The authors declare that they have no competing interests. 


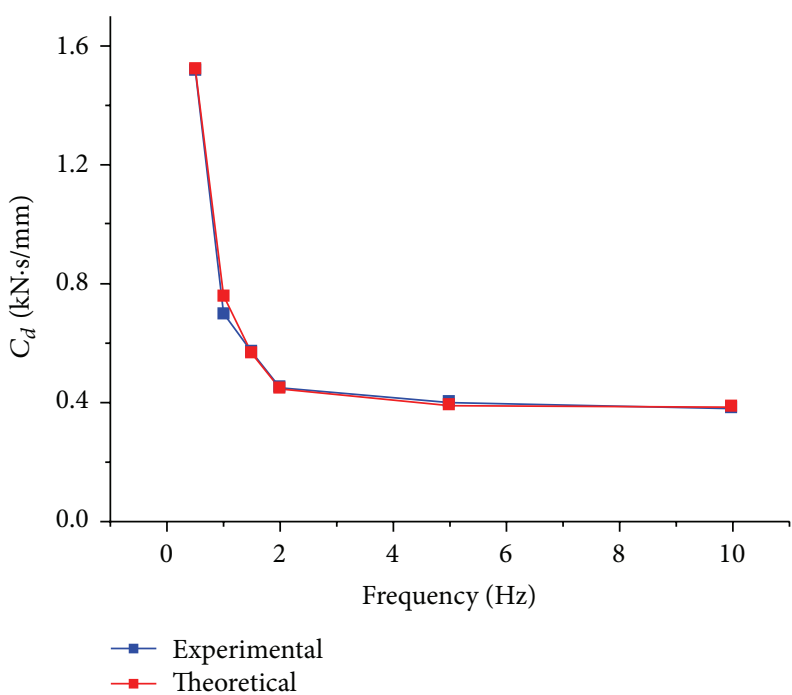

(a) At $225 \%$ strain

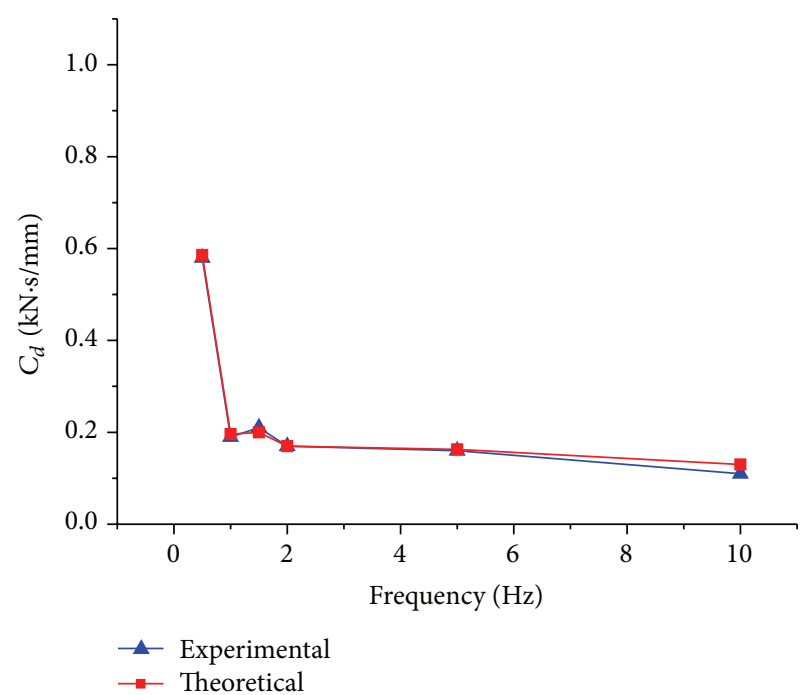

(b) At $450 \%$ strain

FIgURE 8: Model simulation of the equivalent damping coefficient.

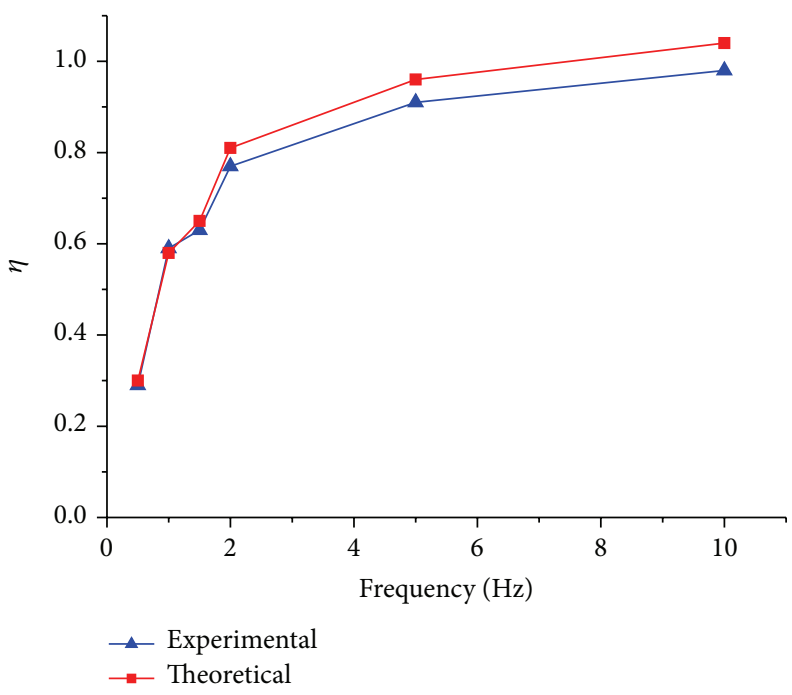

(a) At $225 \%$ strain

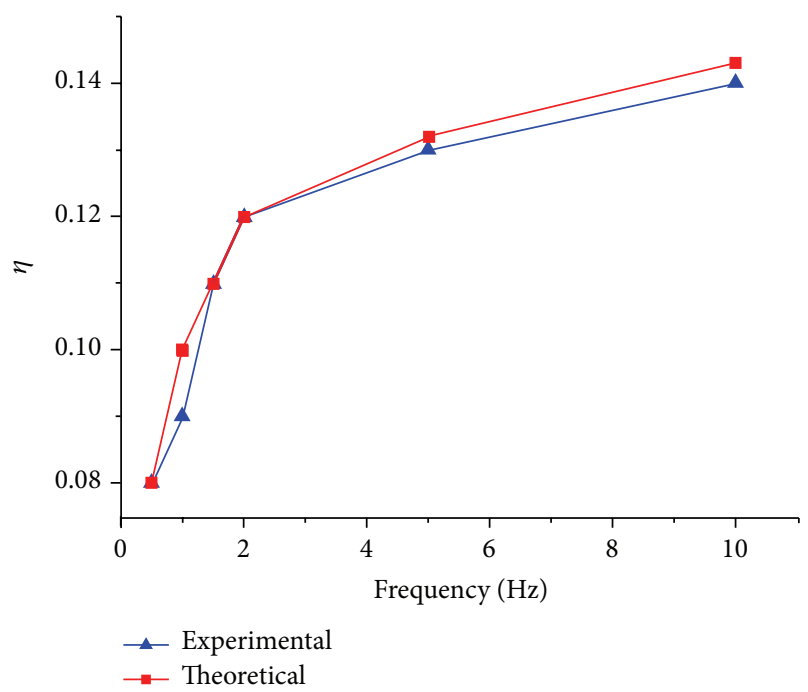

(b) At $450 \%$ strain

Figure 9: Model simulation of the loss factor.

\section{Acknowledgments}

The authors wish to acknowledge the National Science Foundation of China (51278104) and Key Projects of Application Development Plan in Chongqing (cstc2014yykfB30003) in connection with this paper.

\section{References}

[1] C. Christopoulos and A. Filiatrault, Principles of Passive Supplemental Damping and Seismic Isolation, IUSS Press, Pavia, Italy, 2006.

[2] G. Zhao, P. Pan, J. Qian, and J. Lin, "Experimental study of viscoelastic dampers subjected to large deformation," Journal of Building Structures, vol. 33, no. 10, pp. 126-133, 2012.
[3] S. S. Tezcan and O. Uluca, "Reduction of earthquake response of plane frame buildings by viscoelastic dampers," Engineering Structures, vol. 25, no. 14, pp. 1755-1761, 2003.

[4] T. Pritz, "Five-parameter fractional derivative model for polymeric damping materials," Journal of Sound and Vibration, vol. 265, no. 5, pp. 935-952, 2003.

[5] R. M. Christensen, Theory of Viscoelasticity: An Introduction, Academic Press, New York, NY, USA, 1971.

[6] S. W. Park, "Analytical modeling of viscoelastic dampers for structural and vibration control," International Journal of Solids and Structures, vol. 38, no. 44-45, pp. 8065-8092, 2001.

[7] A. Aprile, J. A. Inaudi, and J. M. Kelly, "Evolutionary model of viscoelastic dampers for structural applications," Journal of Engineering Mechanics, vol. 123, no. 6, pp. 551-560, 1997. 
[8] A. Palmeri, F. Ricciardelli, A. De Luca, and G. Muscolino, "State space formulation for linear viscoelastic dynamic systems with memory," Journal of Engineering Mechanics, vol. 129, no. 7, pp. 715-724, 2003.

[9] T. Hatada, T. Kobori, M. Ishida, and N. Niwa, "Dynamic analysis of structures with Maxwell model," Earthquake Engineering \& Structural Dynamics, vol. 29, no. 2, pp. 159-176, 2000.

[10] K.-W. Min, J. Kim, and S.-H. Lee, "Vibration tests of 5-storey steel frame with viscoelastic dampers," Engineering Structures, vol. 26, no. 6, pp. 831-839, 2004.

[11] K. C. Chang, T. T. Soong, S.-T. Oh, and M. L. Lai, "Seismic behavior of steel frame with added viscoelastic dampers," Journal of Structural Engineering, vol. 121, no. 10, pp. 1418-1426, 1995.

[12] J. D. Ferry, Viscoelastic Properties of Polymers, John Wiley \& Sons, New York, NY, USA, 1980.

[13] N. W. Tschoegl, The Phenomenological Theory of Linear Viscoelastic Behavior, Springer, Berlin, Germany, 1989.

[14] V. A. Matsagar and R. S. Jangid, "Viscoelastic damper connected to adjacent structures involving seismic isolation," Journal of Civil Engineering and Management, vol. 11, no. 4, pp. 309-322, 2005.

[15] M. P. Singh and T.-S. Chang, "Seismic analysis of structures with viscoelastic dampers," Journal of Engineering Mechanics, vol. 135, no. 6, pp. 571-580, 2009.

[16] T.-S. Chang and M. P. Singh, "Mechanical model parameters for viscoelastic dampers," Journal of Engineering Mechanics, vol. 135, no. 6, pp. 581-584, 2009.

[17] Y.-T. Chen and Y. H. Chai, "Effects of brace stiffness on performance of structures with supplemental Maxwell model-based brace-damper systems," Earthquake Engineering \& Structural Dynamics, vol. 40, no. 1, pp. 75-92, 2011.

[18] L.-Y. Lu, G.-L. Lin, and M.-H. Shih, “An experimental study on a generalized Maxwell model for nonlinear viscoelastic dampers used in seismic isolation," Engineering Structures, vol. 34, pp. 111-123, 2012

[19] M. Sjöberg and L. Kari, "Non-linear behavior of a rubber isolator system using fractional derivatives," Vehicle System Dynamics, vol. 37, no. 3, pp. 217-236, 2002.

[20] C. J. Black and N. Makris, "Viscous heating of fluid dampers under small and large amplitude motions: experimental studies and parametric modeling," Journal of Engineering Mechanics, vol. 133, no. 5, pp. 566-577, 2007.

[21] R. W. Wolfe, H.-B. Yun, S. Masri, F. Tasbihgoo, and G. Benzoni, "Fidelity of reduced-order models for large-scale nonlinear orifice viscous dampers," Structural Control and Health Monitoring, vol. 15, no. 8, pp. 1143-1163, 2008.

[22] S. Dzierzek, "Experiment-based modeling of cylindrical rubber bushings for the simulation of wheel suspension dynamic behavior," SAE Technical Paper 2000-01-0095, 2000.

[23] N. Makris, M. C. Constantinou, and G. F. Dargush, "Analytical model of viscoelastic fluid dampers," Journal of Structural Engineering, vol. 119, no. 11, pp. 3310-3325, 1993.

[24] R. Lewandowski and B. Chorazyczewski, "Identification of the parameters of the Kelvin-Voigt and the Maxwell fractional models, used to modeling of viscoelastic dampers," Computers and Structures, vol. 88, no. 1-2, pp. 1-17, 2010.

[25] R. Lewandowski and Z. Pawlak, "Dynamic analysis of frames with viscoelastic dampers modelled by rheological models with fractional derivatives," Journal of Sound and Vibration, vol. 330, no. 5, pp. 923-936, 2011.
[26] N. Makris and M. C. Constantinou, "Fractional-derivative maxwell model for viscous dampers," Journal of Structural Engineering, vol. 117, no. 9, pp. 2708-2724, 1991.

[27] M. Lai, P. Lu, and D. Lunsford, "Viscoelastic damper: a damper with linear or nonlinear material," in Proceedings of the 11th World Conference on Earthquake Engineering, Elsevier Science, Mexico City, Mexico, 1996.

[28] Z. D. Xu, Experiment and Study about the (Lead) Viscoelastic Structure, Xian University of Architecture and Technology, Xi'an, China, 2001.

[29] J. H. Xu and A. Q. Li, "Experiments of mechanical properties of super large viscoelastic damping wall under shear loading along transverse direction," Journal of Southeast University (Natural Science Edition), vol. 45, no. 1, pp. 133-138, 2015.

[30] I. Podlubny, Fractional Differential Equations, vol. 198 of Mathematics in Science and Engineering, Academic Press, 1999.

[31] N. Makris, "Complex-parameter Kelvin model for elastic foundations," Earthquake Engineering \& Structural Dynamics, vol. 23, no. 3, pp. 251-264, 1994.

[32] The Japan Society of Seismic Isolation, Passhibu Seishin Kouzou Sekkei. Sekou Manyuaru Sono, The Japan Society of Seismic Isolation, Tokyo, Japan, 2008. 


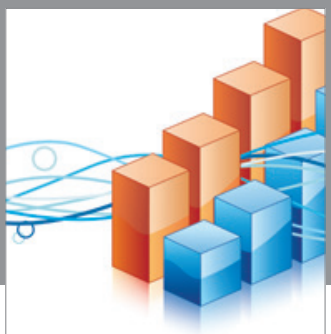

Advances in

Operations Research

vatem alat4

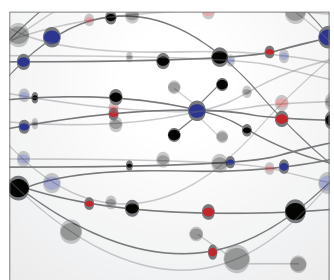

\section{The Scientific} World Journal
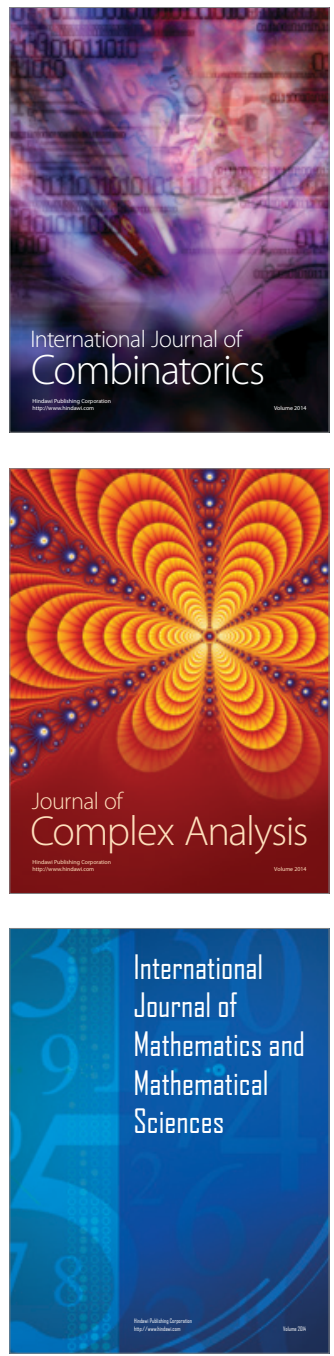
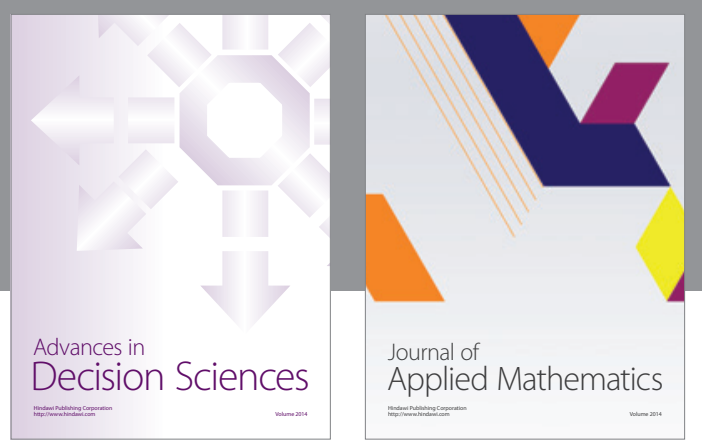

Algebra

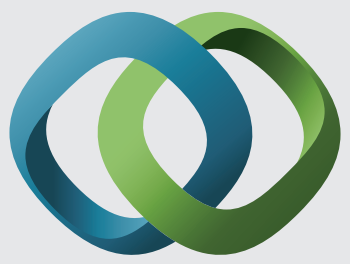

\section{Hindawi}

Submit your manuscripts at

http://www.hindawi.com
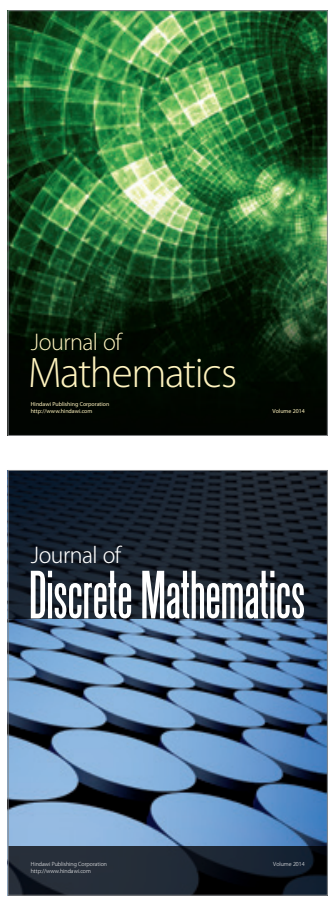

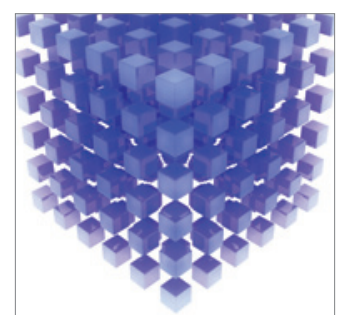

Mathematical Problems in Engineering
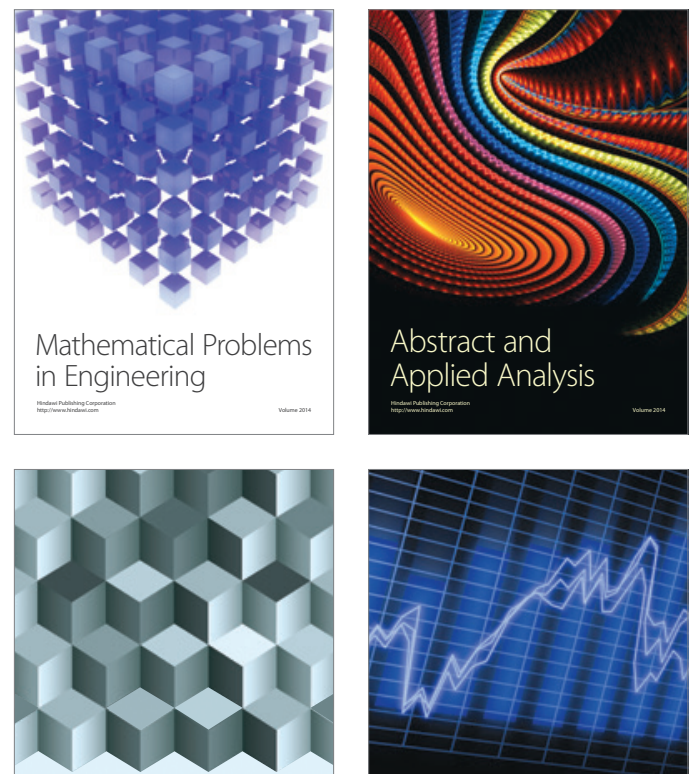

Journal of

Function Spaces

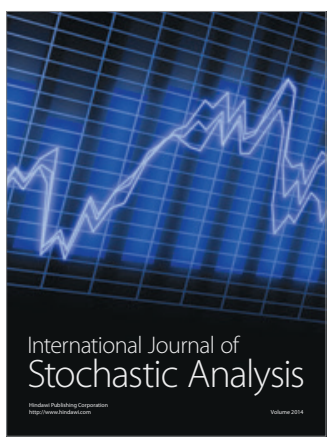

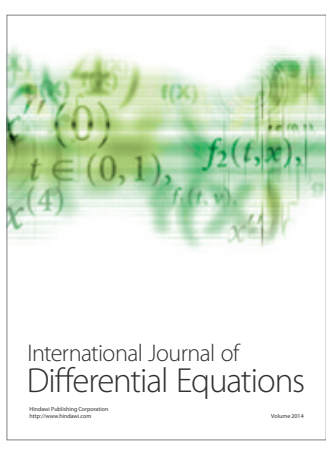
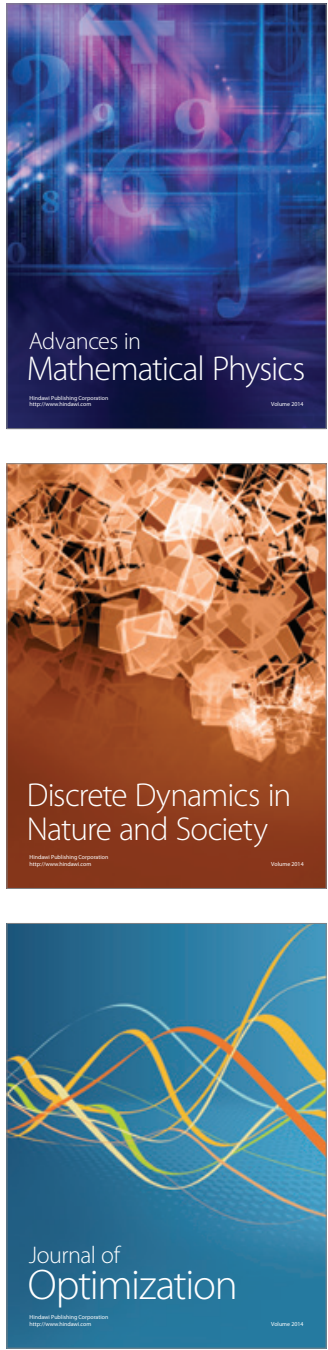